\title{
Prevalence and predictors of smoking in "smoke-free" bars. Findings from the International Tobacco Control (ITC) Europe Surveys
}

Citation for published version (APA):

Nagelhout, G. E., Mons, U., Allwright, S., Guignard, R., Beck, F., Fong, G. T., de Vries, H., \& Willemsen, M. C. (2011). Prevalence and predictors of smoking in "smoke-free" bars. Findings from the International Tobacco Control (ITC) Europe Surveys. Social Science \& Medicine, 72(10), 1643-1651.

https://doi.org/10.1016/j.socscimed.2011.03.018

Document status and date:

Published: 01/05/2011

DOI:

10.1016/j.socscimed.2011.03.018

Document Version:

Publisher's PDF, also known as Version of record

Document license:

Taverne

Please check the document version of this publication:

- A submitted manuscript is the version of the article upon submission and before peer-review. There can be important differences between the submitted version and the official published version of record.

People interested in the research are advised to contact the author for the final version of the publication, or visit the DOI to the publisher's website.

- The final author version and the galley proof are versions of the publication after peer review.

- The final published version features the final layout of the paper including the volume, issue and page numbers.

Link to publication

\footnotetext{
General rights rights.

- You may freely distribute the URL identifying the publication in the public portal. please follow below link for the End User Agreement:

www.umlib.nl/taverne-license

Take down policy

If you believe that this document breaches copyright please contact us at:

repository@maastrichtuniversity.nl

providing details and we will investigate your claim.
}

Copyright and moral rights for the publications made accessible in the public portal are retained by the authors and/or other copyright owners and it is a condition of accessing publications that users recognise and abide by the legal requirements associated with these

- Users may download and print one copy of any publication from the public portal for the purpose of private study or research.

- You may not further distribute the material or use it for any profit-making activity or commercial gain

If the publication is distributed under the terms of Article $25 \mathrm{fa}$ of the Dutch Copyright Act, indicated by the "Taverne" license above, 


\title{
Prevalence and predictors of smoking in "smoke-free" bars. Findings from the International Tobacco Control (ITC) Europe Surveys
}

\author{
Gera E. Nagelhout ${ }^{\mathrm{a}, \mathrm{b}, *}$, Ute Mons ${ }^{\mathrm{c}, \mathrm{d}}$, Shane Allwright ${ }^{\mathrm{e}}$, Romain Guignard ${ }^{\mathrm{f}}$, François Beck ${ }^{\mathrm{f}}$, \\ Geoffrey T. Fong ${ }^{\mathrm{g}, \mathrm{h}}$, Hein de Vries ${ }^{\mathrm{a}}$, Marc C. Willemsen ${ }^{\mathrm{a}, \mathrm{b}}$ \\ ${ }^{a}$ Maastricht University, CAPHRI, The Netherlands \\ ${ }^{\mathrm{b}}$ STIVORO for a Smoke-free Future, The Hague, The Netherlands \\ ${ }^{c}$ Unit Cancer Prevention, WHO Collaborating Centre for Tobacco Control, German Cancer Research Center, Heidelberg, Germany \\ ${ }^{\mathrm{d}}$ Division of Clinical Epidemiology and Aging Research, German Cancer Research Center, Heidelberg, Germany \\ e Department of Public Health and Primary Care, Trinity College Dublin, Ireland \\ ${ }_{\mathrm{f}}^{\mathrm{f}}$ Institut National de Prévention et d'Éducation pour la Santé (INPES), Paris, France \\ ${ }^{\mathrm{g}}$ University of Waterloo, Canada \\ ${ }^{\mathrm{h}}$ Ontario Institute for Cancer Research, Toronto, Canada
}

\section{A R T I C L E I N F O}

Article history:

Available online 30 March 2011

\section{Keywords:}

Ireland

France

The Netherlands

Germany

Smoking

Public policy

Health promotion

Socioeconomic status

Second-hand smoke

\begin{abstract}
A B S T R A C T
National level smoke-free legislation is implemented to protect the public from exposure to second-hand tobacco smoke (SHS). The first aim of this study was to investigate how successful the smoke-free hospitality industry legislation in Ireland (March 2004), France (January 2008), the Netherlands (July 2008), and Germany (between August 2007 and July 2008) was in reducing smoking in bars. The second aim was to assess individual smokers' predictors of smoking in bars post-ban. The third aim was to examine country differences in predictors and the fourth aim was to examine differences between educational levels (as an indicator of socioeconomic status). This study used nationally representative samples of 3147 adult smokers from the International Tobacco Control (ITC) Europe Surveys who were surveyed pre- and post-ban. The results reveal that while the partial smoke-free legislation in the Netherlands and Germany was effective in reducing smoking in bars (from $88 \%$ to $34 \%$ and from $87 \%$ to $44 \%$, respectively), the effectiveness was much lower than the comprehensive legislation in Ireland and France which almost completely eliminated smoking in bars (from $97 \%$ to $3 \%$ and from $84 \%$ to $3 \%$ respectively). Smokers who were more supportive of the ban, were more aware of the harm of SHS, and who had negative opinions of smoking were less likely to smoke in bars post-ban. Support for the ban was a stronger predictor in Germany. SHS harm awareness was a stronger predictor among less educated smokers in the Netherlands and Germany. The results indicate the need for strong comprehensive smoke-free legislation without exceptions. This should be accompanied by educational campaigns in which the public health rationale for the legislation is clearly explained.
\end{abstract}

(c) 2011 Elsevier Ltd. All rights reserved.

\section{Introduction}

National level smoke-free legislation is implemented to protect the public from exposure to second-hand tobacco smoke (SHS) (World Health Organization, 2003). It is a key policy under the World Health Organization (WHO) Framework Convention on Tobacco Control (FCTC), which has, as of September 2010 been ratified by over 170 countries. Smoke-free legislation is being implemented in various settings and is more successful in reducing

\footnotetext{
* Corresponding author. STIVORO, PO Box 16070, 2500 BB, The Hague, The Netherlands. Tel.: +31 7031204 23; fax: +31 703120495 .

E-mail address: gnagelhout@stivoro.nl (G.E. Nagelhout).
}

SHS in some settings than in others. Smoke-free bars are often less successful in reducing SHS than smoke-free restaurants or workplaces (Borland et al., 2006; Thrasher, Pérez-Hernández, Swayampakala, Arillo-Santillán, \& Bottai, 2010). Many consider bars as the "last bastion" of socially acceptable smoking (Magzamen \& Glantz, 2001). Therefore, the tobacco industry fights harder to keep bars from becoming smoke-free than in any other setting (Ling \& Glantz, 2002). This has resulted in lower rates of compliance with smoking bans in bars and designated smoking rooms in bars being permitted in a considerable number of countries (Magzamen \& Glantz, 2001; Smoke Free Partnership, 2006).

Studies have shown that comprehensive smoke-free legislation leads to more reductions in exposure to SHS and improvements in 
health than legislation with designated smoking rooms or other exceptions (Fernandez et al., 2009; World Health Organization, 2007b). This implies that the comprehensiveness of the legislation affects the level of smoking that may remain in bars after the implementation. However, individual smokers' characteristics may also affect whether smokers choose to smoke in bars post-ban. Identifying these characteristics may help to deal with the issue of continued smoking in bars after the implementation of smoke-free legislation.

In this study we used data from the International Tobacco Control (ITC) Europe Surveys, in which nationally representative probability samples of adult smokers were surveyed before and after the implementation of national level smoke-free legislation. According to the International Tobacco Control's conceptual model, support for the ban and SHS harm awareness are policy-specific variables that are immediately affected by the implementation of smoke-free legislation (Fong, Cummings, et al., 2006). Psychosocial variables that are possible mediators of the relationship between these policy-specific variables and smoking in bars post-ban are smokers' attitudes towards smoking (Sheldon, 2010) and perceived societal approval of smoking (Brown, Moodie, \& Hastings, 2009). Findings from baseline ITC Project surveys showed that support for the ban (Borland et al., 2006; Li et al., 2010; Yong et al., 2010) SHS harm awareness, smokers' attitudes towards smoking, and perceived societal approval of smoking (Li et al., 2010) were associated with smoking in the hospitality industry. However, these findings were cross-sectional, and the studied countries did not have national level smoke-free hospitality industry legislation in place at the time of the survey. In the current study, we tested whether pre-ban support for the ban, SHS harm awareness, smokers' attitudes towards smoking, and perceived societal approval of smoking were predictors of smoking in bars after implementation of national level smoke-free legislation.

The benefits of smoke-free bars are likely to be higher among people from lower socioeconomic status (SES) groups because they are more likely to smoke and to be employed in bars (European Commission, 2007). However, compliance with the ban may be lower among low SES groups (Eadie et al., 2008). In the current study, we examine differences between SES groups in predictors of smoking in bars post-ban. Identifying these differences may help in designing interventions that are effective in decreasing smoking in bars post-ban among low SES groups.

The prevalence and predictors of smoking in bars post-ban can be different between countries, due to cultural differences or the comprehensiveness of the smoke-free legislation. In the current study, we compared prevalence and predictors of smoking in bars after the comprehensive smoke-free bar legislation in Ireland and France and the partial smoke-free bar legislation in the Netherlands and Germany. First, we describe how the battle over smoke-free bars was fought in these four countries (see Table 1 ).

\section{Ireland}

Ireland was the first European country to implement nationwide smoke-free workplace legislation. With support from both government and opposition parties, smoking was banned from all indoor workplaces from March 2004 (Howell, 2004; McNicholas, 2004). Violations of the legislation carry a fine of up to $€ 3000$ for the smoker and the owner.

Prior to the implementation of the legislation, a health alliance was formed between government departments, the Minister for Health, health authorities, nongovernmental organisations, health care professional organisations, the newly formed Office of Tobacco Control and the trade union movement, to argue in favour of the legislation using consistent messaging (Fahy, Trench, \& Clancy,

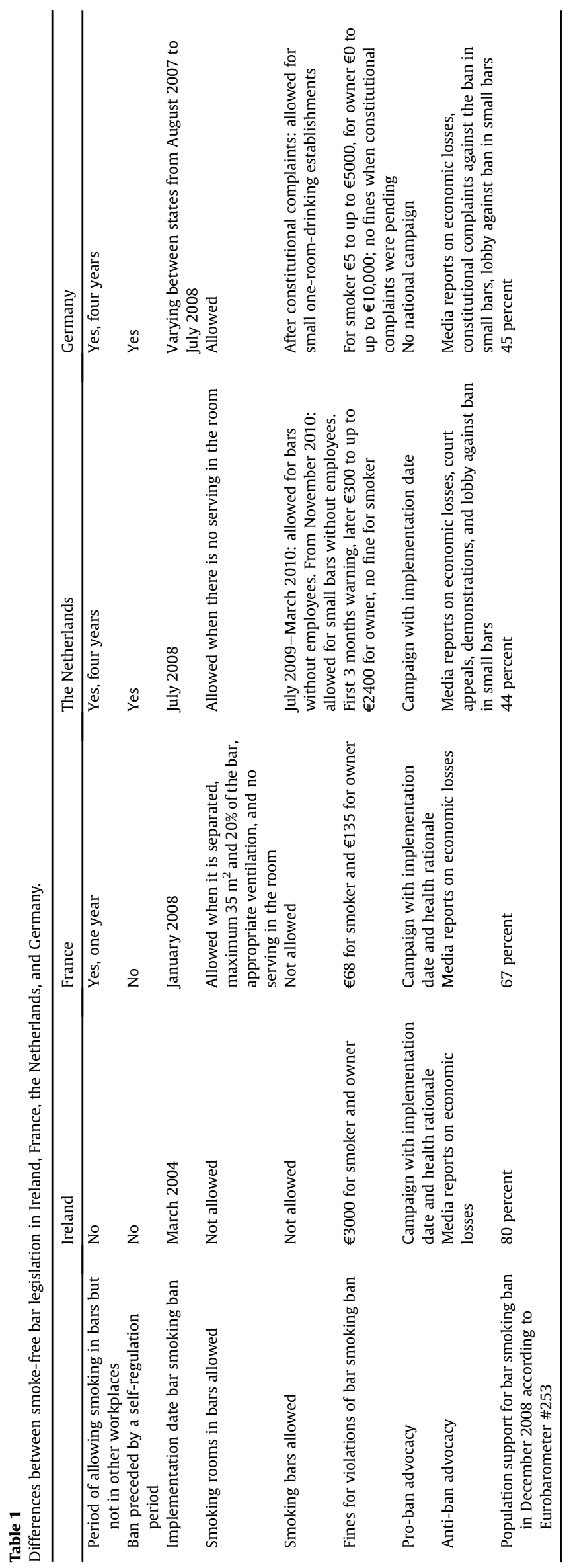


2009; Howell \& Allwright, 2005). They all positioned the legislation as a civil society public health initiative with the primary objective of protecting workers from the harmful effects of SHS. The Office of Tobacco Control created a television and radio campaign in which the health effects of SHS were explained and the date of implementation of the legislation was communicated (Allwright, 2004). An alliance of vested interests came together under the banner of the "Irish Hospitality Industry Alliance" (IHIA) to co-ordinate a campaign of opposition. This Alliance released a report on predicted economic consequences of the legislation and argued that the legislation could not be enforced due to the country's pub culture. Ties between the Alliance and the tobacco industry were suspected but not confirmed (McNicholas, 2004). Pro-ban and antiban advocates received a similar amount of media attention (Fahy et al., 2009).

An extensive evaluation of the Irish smoke-free legislation (Fong, Hyland, et al., 2006) found dramatic declines in reported smoking in all venues post-ban. Furthermore, there was significantly stronger support for the smoke-free legislation post-ban among smokers and non-smokers compared to England, which did not have smoke-free legislation at that time. In addition, the legislation was accompanied by an increase in smoke-free homes, contrary to the fears of some that smoke-free public places could result in more smoking at home.

Although many feared that the Irish pub culture would prevent the legislation from succeeding, the legislation proved to be an immediate success (Howell, 2004; McNicholas, 2004; Office of Tobacco Control, 2004). The Irish people chose the smoke-free legislation as the most positive event that happened in Ireland in 2004 (Howell \& Allwright, 2005). An EU-wide survey in December 2008 revealed that 80 percent of the Irish population supported the smoke-free bar legislation, which was considerably higher than the European average of 65 percent (European Commission, 2009).

\section{France}

France implemented nationwide smoke-free legislation in all enclosed public areas, workplaces, hospitals, schools and transport from February 2007, but made an exception for the hospitality industry until January 2008. Since the smoke-free hospitality industry legislation permits enclosed smoking rooms under very strict conditions - areas separated from the rest of the clientèle, maximum $35 \mathrm{~m}^{2}$ and 20 percent of the establishment, appropriate ventilation, and no service in the room - they are not common. Smokers receive $\mathrm{a} € 68$ fine for violations and venue owners a $€ 135$ fine when the conditions for smoking rooms are not met or when there are no no-smoking signs. When venue owners actively incite violations of the law, the public prosecutor decides on the fine.

Several associations actively argued for the legislation: among others the national association against tobacco smoking (Comité National Contre le Tabagisme, CNCT), the non-smokers' rights association (Droit des Non-Fumeurs, DNF), and the national institute for prevention and health education (Institut National de Prévention et d'Éducation pour la Santé, INPES). The Institut National started campaigning against exposure to SHS in 2004 with television and radio commercials, and posters. The government ran a television, radio, print, and internet campaign at the beginning of 2007 in which the date of implementation of the legislation was communicated and the health effects of SHS were explained. The Comité National ran three television commercials in January 2008. One of them showed restaurant employees working, with a voiceover asking "do you know what risks a restaurant employee has to take?" Opposition to the legislation came mainly from bar owners and tobacconists. Their main argument against the legislation was fear of economic losses, since they already faced a 35 percent decrease in the number of cigarettes sold in 2004 compared to 2002, because of price increases in 2003 and 2004.

At the end of 2008, 67 percent of the French population supported the smoke-free bar legislation, which was slightly higher than the European average (European Commission, 2009).

\section{The Netherlands}

The Dutch smoke-free workplace legislation was implemented in January 2004, but excluded the hospitality industry. A selfregulation plan was arranged with the hospitality industry that should have resulted in completely smoke-free restaurants and hotels and mostly smoke-free bars and discos by the end of 2008 . These results were not achieved, which caused the government to decide to implement smoke-free hospitality industry legislation from July 2008. Enclosed smoking rooms in the hospitality industry were permitted, but serving was not allowed in these rooms. After a period of three months in which venue owners only got a warning for violations, venue owners were fined $€ 300$ for the first violation and up to $€ 2400$ for the fourth violation within five years. Although the legislation was intended to protect employees from exposure to SHS, venues without employees were also obliged to ban smoking. This was considered discriminatory by two Dutch courts, with the consequence that the legislation was temporarily suspended for bars without employees from July 2009. In March 2010 the Dutch Supreme Court ruled that the legislation was not discriminatory, and from that date, the legislation applied to all bars again. However, the new Dutch government is currently considering permanently suspending the legislation for bars smaller than $70 \mathrm{~m}^{2}$ without employees and since November 2010 has not fined these venues for allowing smoking.

The Ministry of Health ran a television, radio, print and internet campaign from May to September 2008 in which only the date of implementation of the smoke-free bar legislation was communicated and no reference to health consequences of SHS was made. The television commercial of this campaign showed a man dressed as a large cigarette being thrown out of hospitality industry venues onto the street. The Dutch expert centre on tobacco control (STIVORO) ran a television, radio, print, and internet smoking cessation campaign, but the smoke-free legislation and SHS were not mentioned in this campaign. An organisation "Red de Kleine Horeca Ondernemer" ("Save the small hospitality industry entrepreneur") was formed by small bars to argue against the legislation. Ties between this organisation and the tobacco industry were confirmed by investigative journalism (Baltesen \& Rosenberg, 2009). The organisation financed court appeals, organised demonstrations, and lobbied for an exemption to the legislation for small bars. Newspaper coverage on the smoke-free legislation was mostly negative towards the legislation, with the economic aspects of the legislation dominating the coverage.

At the end of 2008, six months after the implementation of the legislation, only 44 percent of the Dutch population supported the smoke-free bar legislation, which was the lowest amongst all European countries (European Commission, 2009).

\section{Germany}

The German workplace regulation from 2004 required employers to effectively protect employees from SHS, but workplaces with public access, such as the hospitality industry, were excluded from this obligation. An agreement between the German Ministry of Health and the DEHOGA, the German hotel and restaurant association, was formed to improve the protection of non-smokers in hospitality venues. This self-regulation was declared a failure by the Ministry of Health in February 2007. Following an extensive public 
debate, a national law banning smoking in federal buildings and public transport was implemented in September 2007. Between August 2007 and July 2008, each of Germany's 16 states enacted smoke-free legislation, banning smoking in educational, recreational, health and state institutions and in bars and restaurants.

Regarding the smoke-free hospitality industry legislation, implementation dates, fines, and rules for smoking rooms varied between the federal states. Only one state had total smoke-free legislation at first (Bavaria), and most states allowed smoking in designated smoking rooms, but prohibited smoking in one-room bars and pubs. These exceptional rules caused constitutional complaints by venue owners who feared economic disadvantages. In July 2008 the Federal Constitutional Court ruled that the state laws were unconstitutional on the ground that they gave undue advantage to owners of venues with two or more rooms. The court gave the state legislators until 31 December 2009 to either remove all exceptions or to extend them to all hospitality owners. So although the court declared that a total smoking ban would have been constitutional, they suggested permitting smoking in drinking establishments without food service, which are smaller than $75 \mathrm{~m}^{2}$, do not have a separate smoking room, and do not allow persons under 18 years to enter (German Constitutional Court, 2008). All federal states followed this suggestion at first, so that at the International Tobacco Control follow-up survey, all states allowed smoking rooms in restaurants and in bars and pubs, and all states allowed smoking in small one-room-drinking establishments. The fines for violations of the smoke-free legislation vary from state to state. While Baden-Württemberg does not require fines for noncompliant venue owners, the fines in the other states vary from $€ 50-€ 500$ in Hamburg and Thüringen to up to $€ 10,000$ in Mecklenburg-Vorpommern. Fines for non-compliant smokers vary from $€ 5-€ 100$ in Brandenburg to up to $€ 5000$ in Saxony. When the decision of the German Constitutional Court was pending, there was no enforcement of penalties. There was no national media campaign preceding the smoke-free laws.

At the end of 2008, 45 percent of the German population supported the smoke-free bar legislation, which was similar to the low level of support in the Netherlands (European Commission, 2009).

\section{Research questions}

This study focused on smokers reporting that they themselves have smoked in bars after the implementation of national smokefree hospitality industry legislation. We refer to this behaviour as "smoking in bars post-ban". In Ireland, smoking in bars post-ban equates to non-compliance with the ban, as smoking is completely prohibited in bars in Ireland. In France, Germany, and the Netherlands, smoking in bars post-ban is either non-compliance or reflects smoking in smoking rooms or (in Germany) smoking in bars where smoking is allowed.

The present study aims to answer the following research questions: (1) what is the prevalence of smoking in bars pre- and post-ban in Ireland, France, the Netherlands, and Germany? (2) are support for the ban, SHS harm awareness, smokers' attitudes towards smoking, and perceived societal approval of smoking predictors of smoking in bars post-ban? (3) are there differences among countries in the predictors of smoking in bars post-ban? (4) are there differences between SES groups in the predictors of smoking in bars post-ban?

\section{Methods}

\section{Sample}

Before the implementation of the smoke-free bar legislation in Ireland, France, the Netherlands, and Germany, 6393 smokers aged 18 years and older were surveyed. Smokers were defined as having smoked at least 100 cigarettes in their lifetime and currently smoke at least once per month. Post-ban 4634 baseline smokers were followed up (72.5\% follow-up). See Table 2 for fieldwork periods and sample sizes for each country.

Smokers who were followed up and who were lost to follow-up did not differ by gender, educational level, number of cigarettes per day, and time before smoking the first cigarette of the day. However, smokers who were lost to follow-up were younger $(M=38.3, \mathrm{SD}=14.4)$ than smokers who were followed up $(M=42.3, \mathrm{SD}=14.3 ; t=-9.88, p<0.001)$.

Respondents were recruited using probability sampling methods with fixed line telephone numbers selected at random from the population of each country. The Netherlands sample differed in that most respondents were surveyed using web interviewing ( $n=1668$ of baseline sample of 2072) instead of telephone interviewing (Nagelhout et al., 2010). The Dutch web sample was drawn from a large probability-based database with respondents who had indicated their willingness to participate in research on a regular basis. Dutch telephone and web respondents did not differ by age, gender, and number of cigarettes per day. However, web respondents were less educated $\left(\chi^{2}=23.74, p<0.001\right)$, and smoked their first cigarette of the day later than telephone respondents $(t=-3.75, p<0.001)$. Therefore, univariate analyses were carried out separately for the Dutch telephone and web respondents and interviewing mode was added as predictor variable in multivariate analyses. Follow-up rates were considerably higher for the Netherlands web survey (80.1\%) than the Netherlands telephone survey $(73.7 \%)$ and the telephone surveys in the other countries (Ireland $71.8 \%$, France $71.0 \%$, Germany $66.1 \%$ ).

Since the focus of this study is smoking in bars after the implementation of national smoke-free bar legislation, respondents who did not visit bars after the implementation $(n=985)$ were excluded from the analyses. Also, respondents who had quit smoking $(n=606)$ were excluded. In total 1487 of 4634 respondents were excluded leaving 3147 respondents for the analyses (Ireland $n=573$, France $n=820$, the Netherlands $n=1034$ (telephone $n=185$, web $n=849$ ), Germany $n=720$ ).

Table 2

Fieldwork periods and sample sizes for each country, International Tobacco Control (ITC) Europe Surveys.

\begin{tabular}{|c|c|c|c|c|}
\hline & \multicolumn{2}{|l|}{ Pre-ban survey wave } & \multicolumn{2}{|l|}{ Post-ban survey wave } \\
\hline & Fieldwork period & No. of smokers & Fieldwork period & No. of smokers \\
\hline Ireland & December 2003-January 2004 & 1071 & December 2004-January 2005 & 769 \\
\hline France & December 2006-February 2007 & 1735 & September 2008-December 2008 & 1231 \\
\hline The Netherlands & March 2008-April 2008 & $2072^{\mathrm{a}}$ & March 2009-May 2009 & 1632 \\
\hline Germany & July 2007-November 2007 & 1515 & July 2009-October 2009 & 1002 \\
\hline Total & & 6393 & & 4634 \\
\hline
\end{tabular}

a The ITC Netherlands Survey consisted of 2224 smokers aged 15 years and older of whom 1743 were followed up. Smokers aged $15-17$ years were excluded from this study as the other countries only surveyed smokers aged 18 years and older. 


\section{Measurements}

The questions used for the International Tobacco Control Europe surveys were all adapted from the conceptual model and questionnaire of the Four Country survey (Fong, Cummings, et al., 2006). All surveys were cleared for ethics by the Research Ethics Board of the University of Waterloo and when necessary also by the ethics boards in individual countries.

\section{Control variables}

The multivariate analyses controlled for country, interviewing mode, gender, age, educational level, heaviness of smoking, smoking in bar on last visit pre-ban, and bar visiting in last six months. These variables were assessed at the pre-ban surveys. Age was categorised into four groups: 18 to 24,25 to 39,40 to 54, and 55 years and older. Education was categorised into three levels (low, moderate, and high) that were roughly comparable across the four countries because of differences in educational systems. The Heaviness of Smoking Index (HSI) was created as the sum of two categorical measures: number of cigarettes per day and time before smoking the first cigarette of the day. Smoking index values ranged from 0 to 6 and are positively associated with nicotine dependence (Heatherton, Kozlowski, Frecker, Rickert, \& Robinson, 1989). Bar visiting was assessed using the question "In the last 6 months, how often have you visited a drinking establishment such as a bar or pub?".

\section{Policy-specific variables}

Support for a bar smoking ban was assessed at the pre-ban surveys using the question "Do you think smoking should be allowed in all indoor areas, allowed in some indoor areas, or not allowed indoors at all at drinking establishments (bars and pubs)?". This question was used as indicator of support for smokefree legislation in several other studies (Borland et al., 2006; Fong, Hyland, et al., 2006; Li et al., 2010; Yong et al., 2010). SHS harm awareness was assessed at the pre-ban surveys using the question "In the last month, how often, if at all, did you think about the harm your smoking might be doing to other people?". This question was also used in previous studies (Borland et al., 2006; Yong et al., 2010).

\section{Psychosocial mediators}

Smokers' attitudes towards smoking were assessed at the pre-ban surveys using the question "What is your overall opinion of smoking?". This question was used in previous research as predictor of smoking cessation (Hyland et al., 2006). In line with previous research (Brown et al., 2009; Hammond, Fong, Zanna, Thrasher, \& Borland, 2006), perceived societal approval of smoking was assessed at the pre-ban surveys using the statement "Society disapproves of smoking".

\section{Outcome variable}

Smoking in bars was assessed at the pre- and post-ban surveys using the question "Did you smoke at all at the pub or bar during your last visit, either inside or outside?". Respondents who answered "yes" were asked whether they smoked inside the bar, outside or both. Respondents who answered that they smoked inside or both inside and outside were categorised as "smoked inside the bar on last visit".

\section{Analyses}

To examine the prevalence of smoking in bars pre- and post-ban (research question 1), proportions of smokers reporting smoking in bars pre- and post-ban were presented for each country separately. Chi-square tests were conducted to assess differences in country proportions and to assess difference from pre- to post-ban. All analyses have been weighted by age and gender to be representative of the adult smoker population within each country. More details on the weighting procedure can be found in Thompson et al. (2006).

Predictors of smoking in bars post-ban (research question 2) were assessed using multivariate regression mediation analyses using SPSS macros and guidelines developed by Preacher and Hayes (2004), that were adjusted to allow for a binary outcome (Preacher \& Hayes, 2010). Sobel tests were calculated to estimate the strength and significance of mediation effects. In addition, multivariate logistic regression analysis was employed with smoking in bars post-ban as dependent variable. Independent variables were the above mentioned control variables, policy-specific variables, and psychosocial mediators.

Differences between countries (research question 3) in predictors of smoking in bars post-ban were assessed by adding country interactions to the multivariate logistic regression analysis predicting smoking in bars post-ban. As Germany was the country with the highest level of smoking in bars post-ban, this country was chosen as reference for comparison with Ireland, France, and the Netherlands. Added interactions were country by: support for a bar smoking ban, SHS harm awareness, smokers' attitudes towards smoking, and perceived societal approval of smoking.

Differences between SES groups (research question 4) were assessed by adding educational level interactions to the multivariate logistic regression analysis predicting smoking in bars postban. These analyses were done separately for each country. Added interactions were educational level by: support for a bar smoking ban, SHS harm awareness, smokers' attitudes towards smoking, and perceived societal approval of smoking. Educational level was used as indicator of SES, because it contained considerably fewer missing values ( $n=14)$ than income $(n=363)$.

\section{Results}

\section{Prevalence of smoking in bars}

As can be seen in Table 3, the prevalence of smoking in bars was around 90 percent in all countries pre-ban. Smoking in bars decreased significantly from pre-ban to post-ban in each country (Ireland $\chi^{2}=954.91, p<0.001$; France $\chi^{2}=1039.10, p<0.001$; the Netherlands $\chi^{2}=606.55, p<0.001$; Germany $\chi^{2}=299.85$, $p<0.001$ ). The post-ban percentage of smoking in bars significantly differed between countries $\left(\chi^{2}=566.49, p<0.001\right)$ and was lowest in France (2.7\%), followed by Ireland (3.3\%), the Netherlands (34.0\%; telephone survey $44.8 \%$, web survey $31.6 \%$ ), and Germany (43.6\%).

\section{Predictors of smoking in bars}

There were significant between-country differences in the predictor variables, except for gender of respondents (Table 3). Smokers from Ireland and France were younger and less educated than smokers from the Netherlands and Germany. Smokers in France were the least heavy smokers and smokers in Ireland were the heaviest smokers. Smokers from Ireland were the most 
Table 3

Differences between Ireland, France, the Netherlands, and Germany in predictor variables of smoking in bars post-ban (\%).

\begin{tabular}{|c|c|c|c|c|c|}
\hline & $\begin{array}{l}\text { Ireland } \\
(n=573)\end{array}$ & $\begin{array}{l}\text { France } \\
(n=820)\end{array}$ & $\begin{array}{l}\text { The Netherlands } \\
(n=1034)\end{array}$ & $\begin{array}{l}\text { Germany } \\
(n=720)\end{array}$ & $\begin{array}{l}\text { Between country } \\
\text { differences }\end{array}$ \\
\hline \multicolumn{6}{|l|}{ Control variables } \\
\hline \multicolumn{6}{|l|}{ Gender } \\
\hline Male & 53.9 & 55.5 & 54.4 & 57.5 & \multirow[t]{2}{*}{$\chi^{2}(3)=2.16, p=0.540$} \\
\hline Female & 46.1 & 44.5 & 45.6 & 42.5 & \\
\hline \multicolumn{6}{|l|}{ Age } \\
\hline $18-24$ & 19.6 & 19.9 & 13.1 & 14.4 & \multirow[t]{4}{*}{$\chi^{2}(9)=54.03, p<0.001$} \\
\hline $25-39$ & 30.8 & 36.2 & 30.5 & 29.7 & \\
\hline $40-54$ & 32.2 & 32.1 & 35.0 & 37.5 & \\
\hline $55+$ & 17.5 & 11.8 & 21.5 & 18.3 & \\
\hline \multicolumn{6}{|l|}{ Educational level } \\
\hline Low & 66.4 & 39.9 & 33.8 & 20.1 & \multirow[t]{3}{*}{$\chi^{2}(6)=366.43, p<0.001$} \\
\hline Moderate & 21.3 & 39.0 & 44.0 & 38.3 & \\
\hline High & 12.2 & 21.1 & 22.2 & 41.6 & \\
\hline \multicolumn{6}{|c|}{ Heaviness of smoking ${ }^{\mathrm{a}}$} \\
\hline 0 thru 1 & 27.9 & 48.8 & 29.3 & 39.2 & \multirow[t]{3}{*}{$\chi^{2}(6)=130.51, p<0.001$} \\
\hline 2 thru 4 & 59.2 & 48.2 & 63.3 & 55.4 & \\
\hline 5 thru 6 & 12.9 & 3.1 & 7.4 & 5.4 & \\
\hline \multicolumn{6}{|c|}{ Smoking in bar on last visit pre-ban } \\
\hline Yes & 96.7 & 83.6 & 87.8 & 86.9 & \multirow[t]{2}{*}{$\chi^{2}(3)=53.60, p<0.001$} \\
\hline No & 3.3 & 16.4 & 12.2 & 13.1 & \\
\hline \multicolumn{6}{|c|}{ Bar visiting in last six months } \\
\hline Weekly/monthly & 86.9 & 70.0 & 58.3 & 68.2 & \multirow[t]{2}{*}{$\chi^{2}(3)=141.56, p<0.001$} \\
\hline Yearly/never & 13.1 & 30.0 & 41.7 & 31.8 & \\
\hline \multicolumn{6}{|c|}{ Policy-specific variables } \\
\hline \multicolumn{6}{|c|}{ Support for bar smoking ban } \\
\hline Total ban & 12.5 & 13.2 & 8.1 & 6.3 & \multirow[t]{3}{*}{$\chi^{2}(6)=69.34, p<0.001$} \\
\hline Partial ban & 56.5 & 60.8 & 61.3 & 51.2 & \\
\hline No ban & 31.1 & 25.9 & 30.6 & 42.5 & \\
\hline \multicolumn{6}{|c|}{ Think about harm of smoking to others } \\
\hline Very often & 19.3 & 16.7 & 2.0 & 7.5 & \multirow[t]{3}{*}{$\chi^{2}(6)=225.23, p<0.001$} \\
\hline Often/sometimes & 43.8 & 50.2 & 43.5 & 39.9 & \\
\hline Rarely/never & 37.0 & 33.1 & 54.5 & 52.6 & \\
\hline \multicolumn{6}{|c|}{ Psychosocial mediators } \\
\hline \multicolumn{6}{|c|}{ Overall opinion of smoking } \\
\hline Positive & 12.4 & 9.4 & 12.6 & 20.8 & \multirow[t]{3}{*}{$\chi^{2}(6)=561.50, p<0.001$} \\
\hline Negative & 62.9 & 63.4 & 21.7 & 25.1 & \\
\hline Neutral & 24.7 & 27.2 & 65.7 & 54.2 & \\
\hline \multicolumn{6}{|c|}{ Society disapproves of smoking } \\
\hline Agree & 79.9 & 73.8 & 60.3 & 69.0 & \multirow[t]{3}{*}{$\chi^{2}(6)=199.99, p<0.001$} \\
\hline Disagree & 13.6 & 16.2 & 10.6 & 17.5 & \\
\hline Neutral & 6.5 & 10.0 & 29.0 & 13.5 & \\
\hline
\end{tabular}

${ }^{a}$ Heaviness of smoking is used as continuous variable in the regression analysis.

frequent bar visitors and smokers from the Netherlands the least frequent. Smokers from Ireland and France more often supported smoke-free bars, more often thought about the harm of smoking to others, more often thought negative of smoking, and more often thought that society disapproves of smoking than smokers in Germany and the Netherlands.

The multiple regression mediation analyses showed that both the policy-specific variables and the psychosocial mediators significantly predicted smoking in bars post-ban (Fig. 1). Sobel tests showed that the inclusion of smokers' attitudes towards smoking as mediator significantly decreased the influence of support for the ban $(z=2.29, p=0.022)$ and SHS harm awareness $(z=2.53, p=0.012)$ on smoking in bars post-ban. Also, the inclusion of perceived societal approval of smoking as mediator significantly decreased the influence of support for the ban $(z=2.61, p=0.009)$ and SHS harm awareness $(z=3.68, p<0.001)$ on smoking in bars post-ban. Since the influence of the policyspecific variables on smoking in bars post-ban was still significant after controlling for the psychosocial mediators, we can conclude that there is partial mediation. Mediation analyses by country did not show significant mediation effects, indicating that the mediation effects are small.

A multivariate logistic regression analysis showed that country was the most important predictor of prevalence of smoking in bars post-ban. Smokers from the Netherlands and Germany were more likely to smoke in bars post-ban than smokers from Ireland and France (OR Ireland $=0.03,95 \% \mathrm{CI}=0.02-0.05$; OR France $=0.03$, $95 \% \mathrm{CI}=0.02-0.05 ;$ OR the Netherlands $=0.96,95 \%$ $\mathrm{CI}=0.65-1.43$; Germany is the reference category). Furthermore, there was more smoking in bars post-ban by telephone respondents (versus web respondents from the Netherlands), male smokers, younger smokers, less educated smokers, heavier smokers, smokers who smoked in bars pre-ban, and smokers who visited bars more often (data not shown). More support for the ban and very often thinking about the harm of smoking to others was negatively associated with smoking in bars post-ban (Table 4). Moreover, a negative opinion of smoking was significantly associated with a smaller likelihood of smoking in bars post-ban.

\section{Differences between countries}

Table 4 shows the multivariate logistic regression analysis for all countries together and the analyses separately for each country. Country interaction analyses with Germany as reference showed that support for the ban was a stronger predictor in Germany than in Ireland and the Netherlands (the interaction with France was not significant). There were also interactions found between attitudes towards smoking and perceived societal approval of smoking in 


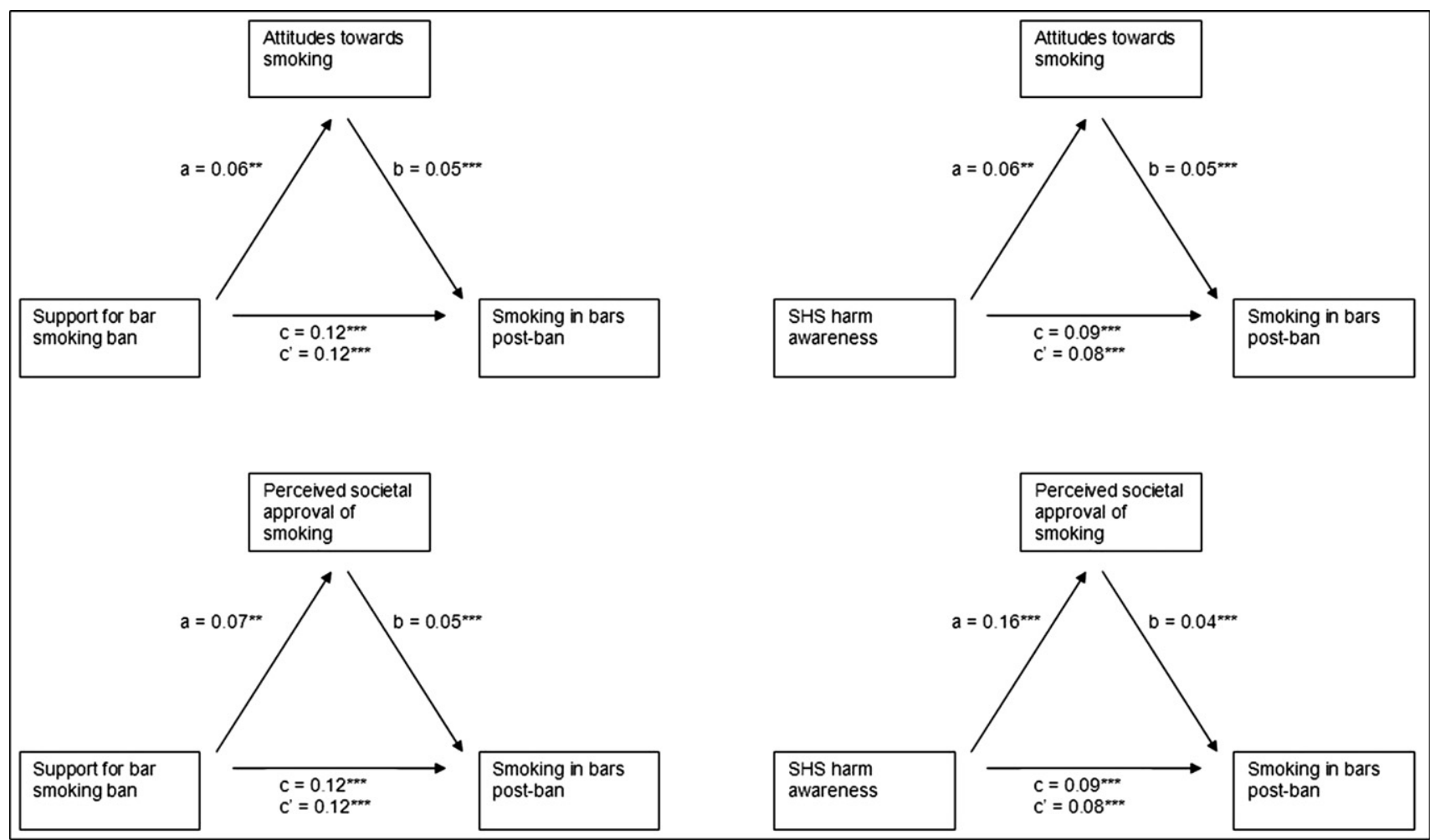

$* * \mathrm{p}<0.01, * * * \mathrm{p}<0.001$

$\mathrm{a}=$ Bèta of policy-specific variable on psychosocial mediator

$\mathrm{b}=$ Odds Ratio of psychosocial mediator on smoking in bars post-ban controlling for the effect of the policy-specific variable

$\mathrm{c}=$ Odds Ratio of policy-specific variable on smoking in bars post-ban

$\mathrm{c}^{\prime}=$ Odds Ratio of policy-specific variable on smoking in bars post-ban controlling for the effect of the psychosocial mediator

Fig. 1. Multiple regression mediation analyses for two psychosocial mediators mediating the relationship between two policy-specific variables and smoking in bars post-ban.

France compared to Germany. However, probably due to few French smokers smoking in bars post-ban, the main effects were either not significant or had a very large confidence interval, suggesting that these results may not be reliable.

\section{Differences between SES groups}

There were significant interactions between educational level and the extent to which the policy-specific variables and the

Table 4

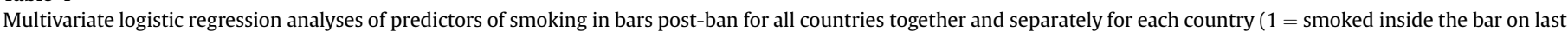
visit, $0=$ did not smoke inside the bar on last visit).

\begin{tabular}{|c|c|c|c|c|c|}
\hline & $\begin{array}{l}\text { All countries }(n=2422) \\
\text { Adjusted }^{\mathrm{a}} \text { OR }(95 \% \mathrm{CI})\end{array}$ & $\begin{array}{l}\text { Ireland }(n=489) \\
\text { Adjusted OR }(95 \% \mathrm{CI})\end{array}$ & $\begin{array}{l}\text { France }(n=707) \\
\text { Adjusted OR }(95 \% \mathrm{CI})\end{array}$ & $\begin{array}{l}\text { The Netherlands }(n=702) \\
\text { Adjusted OR }(95 \% \mathrm{CI})\end{array}$ & $\begin{array}{l}\text { Germany }(n=524) \\
\text { Adjusted OR }(95 \% \mathrm{CI})\end{array}$ \\
\hline \multicolumn{6}{|c|}{ Policy-specific variables } \\
\hline \multicolumn{6}{|c|}{ Support for bar smoking ban } \\
\hline Total ban & $0.44(0.26-0.75)^{* *}$ & $1.56(0.23-10.68)$ & $0.27(0.02-3.03)$ & $0.67(0.34-1.35)$ & $0.19(0.07-0.53)^{* *}$ \\
\hline Partial ban & $0.72(0.58-0.91)^{* *}$ & $1.30(0.42-3.97)$ & $0.58(0.18-1.89)$ & $0.84(0.61-1.17)$ & $0.53(0.36-0.77)^{* * *}$ \\
\hline No ban & 1.00 & 1.00 & 1.00 & 1.00 & 1.00 \\
\hline \multicolumn{6}{|c|}{ Think about harm of smoking to others } \\
\hline Very often & $0.42(0.23-0.77)^{* *}$ & $0.25(0.03-2.39)$ & $0.35(0.07-1.77)$ & $0.29(0.07-1.24)$ & $0.50(0.21-1.17)$ \\
\hline Often/sometimes & $1.01(0.80-1.26)$ & $1.36(0.47-3.95)$ & $0.71(0.22-2.32)$ & $0.94(0.69-1.29)$ & $1.16(0.79-1.72)$ \\
\hline Rarely/never & 1.00 & 1.00 & 1.00 & 1.00 & 1.00 \\
\hline \multicolumn{6}{|c|}{ Psychosocial mediators } \\
\hline \multicolumn{6}{|c|}{ Overall opinion of smoking } \\
\hline Positive & $1.01(0.75-1.36)$ & $4.61(0.76-27.92)$ & $19.80(1.96-199.84)^{*}$ & $0.78(0.50-1.21)$ & $1.17(0.74-1.85)$ \\
\hline Negative & $0.70(0.54-0.93)^{*}$ & $2.73(0.63-11.93)$ & $8.94(1.13-70.57)^{*}$ & $0.50(0.33-0.77)^{* *}$ & $0.70(0.45-1.11)$ \\
\hline Neutral & 1.00 & 1.00 & 1.00 & 1.00 & 1.00 \\
\hline \multicolumn{6}{|c|}{ Society disapproves of smoking } \\
\hline Agree & $0.97(0.74-1.27)$ & $0.37(0.06-2.43)$ & $0.30(0.09-1.04)$ & $1.11(0.79-1.56)$ & $1.23(0.73-2.07)$ \\
\hline Disagree & $1.31(0.91-1.90)$ & $1.89(0.27-13.50)$ & $0.37(0.07-1.89)$ & $1.17(0.69-2.00)$ & $1.78(0.94-3.40)$ \\
\hline Neutral & 1.00 & 1.00 & 1.00 & 1.00 & 1.00 \\
\hline Nagelkerke $R^{2}$ & 0.40 & 0.16 & 0.28 & 0.14 & 0.27 \\
\hline
\end{tabular}

${ }^{*} p<0.05,{ }^{* *} p<0.01,{ }^{* * *} p<0.001$.

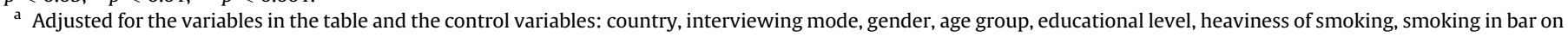
last visit pre-ban, and bar visiting in last six months. 
psychosocial mediators predicted smoking in bars post-ban in the Netherlands and Germany. Highly educated smokers from the Netherlands who were supportive of a partial ban were less likely to smoke in bars post-ban (OR highly educated $=0.53,95 \%$ $\mathrm{CI}=0.26-1.08)$. Moderately educated smokers from the Netherlands who often or sometimes thought about the harm of smoking to others were less likely to smoke in bars (OR moderately educated $=0.54,95 \% \mathrm{CI}=0.34-0.88$ ). Societal approval of smoking was a stronger predictor of smoking in bars among highly educated smokers (OR highly educated $=2.87,95 \% \mathrm{CI}=1.01-8.18$ ). Low and moderately educated smokers from Germany who very often thought about the harm of smoking to others were borderline significantly less likely to smoke in bars (OR low educated $=0.14$, $95 \% \mathrm{CI}=0.02-1.15 ;$ OR moderately educated $=0.23,95 \%$ $\mathrm{CI}=0.05-1.11)$.

\section{Discussion}

Smoking was highly prevalent in bars in Ireland, France, the Netherlands and Germany before these countries implemented national level smoke-free bar legislation. While the partial legislation in the Netherlands and Germany was effective in reducing smoking in bars, the level of effectiveness was much lower than that achieved in Ireland and France. Many bar workers and patrons in the Netherlands and Germany are still exposed to SHS, whereas the comprehensive legislation in Ireland and France almost completely eliminated smoking in bars. Since there is no risk-free minimal level of exposure to SHS (U.S. Department of Health and Human Services, 2006; World Health Organization, 2007b), no countries should settle with less than eliminating smoking in all indoor public places. The Netherlands and Germany should, therefore, aim to further reduce smoking in bars.

This study showed that 'country' was the most important predictor of prevalence of smoking in bars post-ban, with smokers from the Netherlands and Germany more likely to smoke in bars post-ban than smokers from Ireland and France. The weaker smoke-free bar legislation in the Netherlands and Germany compared to Ireland and France (see Table 1) is the most plausible explanation of this finding. The Netherlands and Germany both allowed smoking in bars but not in other workplaces for a period of four years. In this period, the hospitality industry was expected to reduce smoking by means of self-regulation. Both countries eventually banned smoking in bars, but allowed smoking in designated smoking rooms and in small bars. In the Netherlands and some German states, violations of the legislation were not fined in the first months after the implementation of the legislation. Since the exceptions and the moderate level of enforcement probably cause the higher levels of smoking in bars post-ban, we recommend countries to implement smoke-free legislation without exceptions and to enforce the legislation heavily. This corresponds with guidelines and recommendations of the World Health Organization (World Health Organization, 2007a, 2007b) and the European Commission (European Commission, 2007).

In this study, we identified individual smokers' predictors of smoking in bars post-ban. Smokers who were more supportive of the ban, were more aware of the harm of SHS, and who had negative opinions of smoking were less likely to smoke in bars post-ban. There was more support for the ban, SHS harm awareness, negative opinions of smoking, and societal disapproval of smoking in Ireland and France than in the Netherlands and Germany. These predictors can possibly be positively influenced by educational campaigns that clearly explain that the smoke-free legislation is implemented to protect people against harm from exposure to SHS (European Commission, 2007; Smoke Free Partnership, 2006; World Health Organization, 2007a, 2007b).
In Ireland and France several health organisations argued in favour of the legislation in the media, and educational campaigns highlighted the fact that the legislation was intended to protect people against SHS exposure. In the Netherlands and Germany there was less media advocacy from health organisations, and the educational campaign in the Netherlands only communicated the date of the implementation of the legislation and did not explain the health rationale for the legislation. In Germany, there was no national implementation campaign at all. However, since we did not directly study exposure to educational campaigns, we cannot be certain that campaigns would have increased SHS harm awareness and support for the ban. More research is needed to study this further.

According to the ITC conceptual model, each tobacco control policy ultimately has an influence on behaviour by influencing policy-specific variables, which in turn influence psychosocial mediators, which influence policy-relevant outcome behaviours (Fong, Cummings, et al., 2006). Our study showed that smokers' attitudes towards smoking and perceived societal approval of smoking were partial mediators of the relationship between support for the ban and SHS harm awareness on smoking in bars post-ban. Support for the ban and SHS harm awareness also had a direct influence on smoking in bars post-ban. This suggests that increasing support for the ban and SHS harm awareness can lead to less smoking in bars post-ban, even when attitudes and norms about smoking are not affected.

There were some differences between countries in the predictors of smoking in bars post-ban. Greater support for the ban was a stronger predictor in Germany. As the German smoke-free law allows smoking rooms as well as smoking in small bars, smokers from Germany have more options regarding bars than smokers from Ireland, France, and the Netherlands. German smokers can either go to a smoke-free bar, to a bar with a smoking room or to a smoking bar, and this decision would likely influence their smoking behaviour during the time spent at the bar. Assuming that support for the ban reflects preferences regarding smoke-free bar legislation, German smokers supporting smoke-free bars would be more likely to go to smoke-free bars and thus be less likely to smoke in bars.

Smokers with a low educational level were more likely than smokers with a high educational level to smoke in bars post-ban. The predictors of smoking in bars post-ban were also different between smokers from different educational levels. In Germany and the Netherlands, SHS harm awareness was a stronger predictor among less educated smokers. This suggests that smoking in bars post-ban can be decreased among lower SES smokers by communicating about the harm of smoking to others. This is especially urgent for the Netherlands, where only 1 percent of low educated smokers thinks very often about the harm of their smoking to others (compared to 19\% of Irish, 17\% of French, and 9\% of German low educated smokers).

\section{Limitations}

The primary strength of the ITC Project is that findings in one country can be compared with findings in another country (Fong, Cummings, et al., 2006). In a perfect world, the ITC Europe surveys used in this study would have been conducted in parallel, while using exactly the same questions and methods. Unfortunately, practical issues prevented us from doing so. The survey months and years and the time intervals between waves and between the ban and post-ban waves were different between countries, there were demographic differences between countries and the interviewing methods were different for the ITC Netherlands survey. Although we recommend standardization of the methods between countries for future research, we expect the 
influence of these inconsistencies on the pattern of results of the study to be only minor.

Another issue is that it might be perceived as socially undesirable to smoke in bars when there is legislation that bans smoking. Therefore, the point estimates of smoking in bars post-ban presented in this study could be an underestimation of the actual figures. Fortunately, we not only asked about whether smokers have smoked themselves in a bar post-ban, but also about whether they have seen other people smoking. These figures are indeed slightly higher, but show a corresponding pattern: Ireland self $=3 \%$, others $=5 \%$, France self $=3 \%$, others $=4 \%$, the Netherlands self $=34 \%$, others $=36 \%$, Germany self $=44 \%$, others $=50 \%$.

Furthermore, younger smokers had lower follow-up rates. Since younger smokers were more likely to smoke in bars post-ban, this could have led to an underestimation of the point estimates of smoking in bars post-ban.

\section{Conclusion}

In Ireland and France, comprehensive smoke-free legislation almost completely eliminated smoking in bars post-ban. In contrast, the partial legislation in the Netherlands and Germany was much less successful, although this legislation did reduce smoking in bars. Smokers who were more supportive of the ban, were more aware of the harm of SHS, and who had negative opinions of smoking were less likely to smoke in bars post-ban. The results indicate the need for strong comprehensive smoke-free legislation without exceptions. This should be accompanied by educational campaigns in which the public health rationale for the legislation is clearly explained.

\section{Acknowledgements}

The ITC Europe surveys were supported by grants from U.S. National Cancer Institute R01 CA090955 (Ireland wave 1 and 2), Institut National de Prévention et d'Éducation pour la Santé (INPES), Institut National du Cancer (INCa) (France wave 1 and 2), the Netherlands Organisation for Health Research and Development (ZonMw) (the Netherlands wave 1, 2 and 3), German Ministry of Health, Dieter Mennekes-Umweltstiftung, Germany Cancer Research Centre (DKFZ) (Germany wave 1 and 2), Glaxo Smith Kline \#3516601 (Ireland wave 1), and Pfizer (Ireland wave 2). Ute Mons is financially supported by the Klaus Tschira Foundation $\mathrm{gGmbH}$. Jean-Louis Wilquin and Martina Pötschke-Langer have contributed to the writing of the paper. Lorraine Craig, Ruth Loewen, Mary Thompson, Christian Boudreau, and other members of the ITC Project team have contributed with project management, survey development, and data cleaning.

\section{References}

Allwright, S. (2004). Republic of Ireland's indoor workplace smoking ban. British Journal of General Practice, 54, 811-812.

Baltesen, F., \& Rosenberg, E. (2009). Big tobacco pays Dutch opposition to smoking ban. NRC Handelsblad, 1, Rotterdam.

Borland, R., Yong, H.-H., Siahpush, M., Hyland, A., Campbell, S., Hastings, G., et al. (2006). Support for and reported compliance with smoke-free restaurants and bars by smokers in four countries: findings from the International Tobacco Control (ITC) Four Country Survey. Tobacco Control, 15(Suppl. 3), 34-41.

Brown, A., Moodie, C., \& Hastings, G. (2009). A longitudinal study of policy effect (smoke-free legislation) on smoking norms: ITC Scotland/United Kingdom. Nicotine \& Tobacco Research, 11, 924-932.

Eadie, D., Heim, D. MacAskill, S., Ross, A. Hastings, G., \& Davies, J. (2008) A qualitative analysis of compliance with smoke-free legislation in community bars in Scotland: implications for public health. Addiction, 103, 1019-1026.

European Commission (2007). Green paper. Towards a Europe free from tobacco smoke: Policy options at EU level. Brussels: European Commission.

European Commission (2009). Survey on tobacco: Analytical report. Hungary: The Gallup Organisation. Eurobarometer \#253.
Fahy, D., Trench, B., \& Clancy, L. (2009). Communicating contentious health policy: lessons from Ireland's workplace smoking ban. Health Promotion Practice, Published Online First: 08.10.09.

Fernandez, E., Fu, M., Pascual, J. A., Lopez, M. J., Perez-Rios, M., Schiaffino, A., et al. (2009). Impact of the Spanish smoking law on exposure to second-hand smoke and respiratory health in hospitality workers: a cohort study. PLOS ONE, 4(1), e4244

Fong, G. T., Cummings, M., Borland, R., Hastings, G., Hyland, A., Giovino, G., et al. (2006). The conceptual framework of the International Tobacco Control (ITC) policy evaluation project. Tobacco Control, 15(Suppl. 3), 3-11.

Fong, G. T., Hyland, A., Borland, R., Hammond, D., Hastings, G., McNeill, A., et al. (2006). Reductions in tobacco smoke pollution and increases in support for smoke-free public places following the implementation of comprehensive smoke-free workplace legislation in the Republic of Ireland: findings from the ITC Ireland/UK Survey. Tobacco Control, 15(Suppl. 3), 51-58.

German Constitutional Court (2008). Decision of the First Senate from July 30th 2008. Karlsruhe: German Constitutional Court.

Hammond, D., Fong, G. T., Zanna, M. P., Thrasher, J. F., \& Borland, R. (2006). Tobacco denormalization and industry beliefs among smokers from four countries. American Journal of Preventive Medicine, 31, 225-232.

Heatherton, T. F., Kozlowski, L. T., Frecker, R. C., Rickert, W., \& Robinson, J. (1989). Measuring the heaviness of smoking: using self-reported time to the first cigarette of the day and number of cigarettes smoked per day. British Journal of Addiction, 84, 791-800.

Howell, F. (2004). Ireland's workplaces, going smoke free. BMJ, 328, 847-848.

Howell, F., \& Allwright, S. (2005). Smoke-free public places in Ireland: how was it achieved and what has been learnt? In Royal College of Physicians Tobacco Advisory Group (Ed.), Going smoke-free. The medical case for clean air in the home, at work and in public places (pp. 185-196). London: Royal College of Physicians.

Hyland, A., Borland, R., Li, Q., Yong, H.-H., McNeill, A., Fong, G. T., et al. (2006). Individual-level predictors of cessation behaviours among participants in the International Tobacco Control (ITC) Four Country Survey. Tobacco Control, 15(Suppl. 3), 83-94.

Li, X., Li, Q., Dong, L., Sun, B., Chen, J., Yuan, J., et al. (2010). Risk factors associated with smoking behavior in recreational venues: findings from the International Tobacco Control (ITC) China Survey. Tobacco Control, 19(Suppl. 2), i30-i39.

Ling, P. M., \& Glantz, S. A. (2002). Nicotine addiction, young adults, and smoke-free bars. Drug and Alcohol Review, 21, 101-104.

Magzamen, S., \& Glantz, S. (2001). The new battleground: California's experience with smoke-free bars. American Journal of Public Health, 91, 245-252.

McNicholas, W. T. (2004). Controlling passive smoking through legislation in Ireland: an attack on civil liberty or good public health policy? European Respiratory Journal, 24, 337-338.

Nagelhout, G., Willemsen, M., Thompson, M., Fong, G., Van den Putte, B., \& De Vries, H. (2010). Is web interviewing a good alternative to telephone interviewing? Findings from the International Tobacco Control (ITC) Netherlands Survey. BMC Public Health, 10, 351.

Office of Tobacco Control (2004). Smoke-free workplace legislation implementation, six month progress report. Office of Tobacco Control.

Preacher, K. J., \& Hayes, A. F. (2004). SPSS and SAS procedures for estimating indirect effects in simple mediation models. Behavior Research Methods, Instruments, \& Computers, 36, 717-731.

Preacher, K. J., \& Hayes, A. F. (2010). SPSS Sobel macro syntax reference. Retrieved 13.01.11 from http://www.comm.ohio-state.edu/ahayes/SPSS\%20programs/ Sobel\%20syntax.pdf.

Sheldon, T. (2010). Netherlands is told to get tough on smokers as cancer mortality stagnates. BMJ, 340, c3309.

Smoke Free Partnership (2006). Lifting the smokescreen. 10 reasons for a smoke free Europe. Brussels: European Respiratory Society Brussels Office.

Thompson, M. E., Fong, G. T., Hammond, D., Boudreau, C., Driezen, P., Hyland, A., et al. (2006). Methods of the International Tobacco Control (ITC) Four Country Survey. Tobacco Control, 15(Suppl. 3), 12-18.

Thrasher, J. F., Pérez-Hernández, R. P., Swayampakala, K., Arillo-Santillán, E., \& Bottai, M. (2010). Policy support, norms, and secondhand smoke exposure before and after implementation of a comprehensive smoke-free law in Mexico City. American Journal of Public Health, 100, 1789-1798.

U.S. Department of Health and Human Services (2006) The health consequences of involuntary exposure to tobacco smoke: A report of the Surgeon General. Atlanta, GA: U.S. Department of Health and Human Services. Centers for Disease Control and Prevention, Coordinating Center for Health Promotion, National Center for Chronic Disease Prevention and Health Promotion, Office on Smoking and Health.

World Health Organization (2003). WHO framework convention on tobacco control. Geneva, Switzerland: World Health Organization.

World Health Organization (2007a). Guidelines on protection from exposure to tobacco smoke. Geneva: World Health Organization.

World Health Organization (2007b). Protection from exposure to second-hand tobacco smoke. Policy recommendations. Geneva: World Health Organization.

Yong, H.-H., Foong, K., Borland, R., Omar, M., Hamann, S., Sirirassamee, B., et al. (2010). Support for and reported compliance among smokers with smoke-free policies in air-conditioned hospitality venues in Malaysia and Thailand: findings from the International Tobacco Control Southeast Asia Survey. Asia-Pacific Journal of Public Health, 22, 98-109. 